\title{
SHR-Zbtb16 Minimal Congenic Strain Reveals Nutrigenetic Interaction Between Zbtb16 and High-Sucrose Diet
}

\author{
Elena ŠKOLNÍKOVÁ ${ }^{1}$, Lucie ŠEDOVÁ ${ }^{1}$, František LIŠKA ${ }^{1}$, Ondřej ŠEDA ${ }^{1}$ \\ ${ }^{1}$ Institute of Biology and Medical Genetics, First Faculty of Medicine, Charles University, General \\ University Hospital, Prague, Czech Republic
}

Received December 20, 2019

Accepted March 25, 2020

Epub Ahead of Print May 29, 2020

\section{Summary}

Both prenatal and postnatal excessive consumption of dietary sucrose or fructose was shown to be detrimental to health and contributing to pathogenesis of metabolic syndrome. Our knowledge of genetic determinants of individual sensitivity to sucrose-driven metabolic effects is limited. In this study, we have tested the hypothesis that a variation of metabolic syndromerelated gene, Zbtb16 (Zinc Finger and BTB Domain Containing 16 will affect the reaction to high-sucrose diet (HSD) content in "matched" nutritional exposition settings, i.e. maternal HSD with re-exposition to HSD in adulthood vs. standard diet. We compared metabolic profiles of adult males of spontaneously hypertensive rats (SHR) and a single-gene, minimal congenic strain SHR-Zbtb16 fed either standard diet or exposed to HSD prenatally throughout gestation and nursing and again at the age of 6 months for the period of 14 days. HSD exposition led to increased adiposity in both strains and decrease of glucose tolerance and cholesterol (Ch) concentrations in majority of lowdensity lipoprotein (LDL) particle classes and in very large and large high-density lipoprotein (HDL) in SHR-Zbtb16 male offspring. There was a similar pattern of HSD-induced increase of triacylglycerols in chylomicrons and very low-density lipoprotein (VLDL) of both strains, though the increase of (triacylglycerol) TAG content was clearly more pronounced in SHR. We observed significant STRAIN*DIET interactions for the smallest LDL particles as their TAG content decreased in SHR-Zbtb16 and did not change in SHR in response to HSD. In summary, we provide evidence of nutrigenetic interaction between $Z b t b 16$ and HSD in context of pathogenesis of metabolic syndrome.

\section{Key words}

Metabolic syndrome $\bullet$ DOHAD $\bullet$ Maternal diet $\bullet$ Nutrigenetics

\section{Corresponding author}

O. Šeda, Institute of Biology and Medical Genetics, First Faculty of Medicine, Charles University and General University Hospital, Albertov 4, 12800 Prague, Czech Republic. E-mail: oseda@lf1.cuni.cz

The quantitative and qualitative changes of nutrition in early development (Kunes et al. 2015, Nicholas and Ozanne 2019) as well as postnatally (Fabiani et al. 2019) were shown to be tightly connected with pathophysiology of metabolic syndrome (MetS), a clustering of dyslipidemia, hypertension, obesity and insulin resistance. Apart from the traditional environmental factors (diet, physical activity, smoking etc.), a growing body of evidence supports the role of fetal and early life environment in the determination of disease in adulthood, including MetS. Studies in human subjects and animal models have shown that the early environment modulates, or "programs" key hormonal systems and pathways involved in growth, metabolism, coping with stress or reproduction (Fleming et al. 2018). Although the prevalence of MetS and hypertension is highest in the "westernized" societies where maternal excess caloric intake rather than malnutrition is likely to be the prenatal environment, this modality received so far only limited attention. Also, despite the particularly detrimental effect of sucrose and fructose overconsumption in terms of MetS pathogenesis (Khan 
and Sievenpiper 2016, Dehghan et al. 2017), most experimental studies utilized high-fat, or mixed high-fat high-sucrose diet. It is generally perceived that adverse environment during development changes gene expression via epigenomic modulation (DNA methylation, histone acetylation, chromatin remodeling) and leads to physiological or morphological phenotypes associated with disease (Hoffman et al. 2017). On the other hand, we and others observed that there is a tighter interaction between epigenomic and genomic components in the pathogenetic process as some of the outcomes of epigenomic modulations depend on genomic constitution (Pausova et al. 2003, Buresova et al. 2006). In this study, we have tested the hypothesis that a variation of MetSrelated gene, Zbtb16 (Zinc Finger and BTB Domain Containing 16) (Seda et al. 2017b, Bendlova et al. 2017) will affect the reaction to HSD in "matched" nutritional exposition settings (Hanson and Gluckman 2014), i.e. maternal HSD with re-exposition to HSD in adulthood vs. standard diet.

All henceforth-described experiments were approved by the Ethical Committee of the First Faculty of Medicine of the Charles University and by the Ministry of Education, Youth and Sports (protocol no. MSMT14076/2015-14). We used the spontaneously hypertensive rat (SHR/OlaIpcv, RGD ID 631848) and the SHRLx.PD5 ${ }^{\text {PD-Zbtbl6 }}$ single congenic strain (SHR-Zbtb16 hereafter), which was derived from polydactylous rat (PD/Cub, RGD ID 728161) (Sedova et al. 2000, Seda et al. 2002) and carries the Zbtb16 gene of PD origin on the SHR genomic background. As we showed previously, the two strains thus differ only in the variant Zbtb16 gene (Zinc Finger and BTB Domain Containing 16) (Krupkova et al. 2018, Liska et al. 2014). Both strains are highly inbred and maintained by brother $\mathrm{x}$ sister mating at the Institute of Biology and Medical Genetics.

All animals were held under controlled conditions (temperature, humidity) with free access to food and water. Rat dams of SHR and SHR-Zbtb16 strains ( $n=6 /$ strain) were fed standard diet till breeding with corresponding (SHR x SHR, SHR-Zbtb16 x SHRZbtb16) males fed standard diet. After mating, rat dams were placed in the cages individually and fed a corresponding diet - standard diet (STD, ssniff RZ, ssniff Spezialdiäten $\mathrm{GmbH}$, Soest, Germany) for control group and HSD (proteins (19.6 cal\%), fat (10.4 cal\%), carbohydrates (sucrose, $70 \mathrm{cal} \%$ )) for experimental group throughout pregnancy and lactation. The diets differed in the carbohydrate fraction only, with starch in STD vs. sucrose in HSD as a source of carbohydrates; otherwise they contained equal amounts of macro- and micronutrients. The litter size was restricted to 8 pups both in SHR and SHR-Zbtb16 offspring which were weaned after 28 days and fed standard diet till the age of six months. At that time, offspring of the experimental groups of dams ( $n=6 /$ strain) were re-exposed to HSD feeding for 14 days, the offspring of control dams were fed STD. At the end of experiment, all male offspring were subjected to blood draw for metabolic and lipid profile assessment after an 14-hour fast followed by oral glucose tolerance test (OGTT) - intragastric glucose administration to conscious rats by oral gavage $(3 \mathrm{~g} / \mathrm{kg}$ body weight, $30 \%$ aqueous solution); Ascensia Elite Blood Glucose Meter; Bayer HealthCare, Mishawaka, IN, USA; validated by the Institute of Clinical Biochemistry and Laboratory Diagnostics of the First Faculty of Medicine). and sacrifice. The lipid profile was assessed using high performance liquid chromatography (HPLC) for determining $\mathrm{TAG}$ and $\mathrm{Ch}$ concentrations in 20 lipoprotein fractions and the size of major classes of lipoprotein particles as described previously (Usui et al. 2002, Seda et al. 2017a). All statistical analyses were performed using STATISTICA 13.5 (TIBCO Software Inc.). When comparing morphometric and biochemical variables between groups, two-way ANOVA with STRAIN and DIET as major factors were used, followed by post hoc Fisher's test for comparison of the specific pairs of variables. Null hypothesis was rejected whenever $\mathrm{p}>0.05$.

There was no difference in body weight among the male offspring groups. HSD resulted in an increase in visceral and retroperitoneal white adipose tissue mass as well as interscapular brown fat in both strains and in decrease of kidney weight exclusively in SHR (Table 1). The comparison of glucose tolerance revealed the effect of HSD, which was particularly prominent in SHRZbtb16, showing significant increase of area under the glycaemic curve (Fig. 1A) despite rise in fasting insulin (Table 1). Maternal HSD with re-exposition to the same diet in adulthood led to elevated glycemia between $30^{\text {th }}$ and $90^{\text {th }}$ minute after glucose bolus administration in SHR-Zbtb16, while in SHR we observed a distinct reaction pattern with no significant differences between the HSD-exposed and control groups. In this context, we identified a STRAIN*DIET interaction at $60^{\text {th }}$ $(\mathrm{p}=0.00009)$ and $90^{\text {th }}(\mathrm{p}=0.007)$ minutes of OGTT: in control groups, SHR showed higher glucose concentration at $60^{\text {th }}$ minute compared to SHR-Zbtb16, 
whereas opposite was true for the HSD-exposed groups (Fig. 1A). This strain-specific effect could be in part attributable to greater rise in fasting insulin in HSDexposed SHR animals (78 \% compared to $44 \%$ increase in SHR-Zbtb16). We have previously described particular sensitivity of SHR-Zbtb16 to diabetogenic effect of dexamethasone (Krupkova et al. 2018). Since we have previously shown a lack of effect of maternal HSD on standard chow-fed adult male offspring of PD (Sedova et al. 2007) and SHR-Zbtb16 rats and a modest one in SHR (Skolnikova et al. 2017), the observed differences in glycemia course in both SHR and SHR-Zbtb16 experimental groups are most likely attributable to postnatal HSD feeding. While the mechanism connecting the variant Zbtbl6 gene comprising an intronic deletion and one conserved nonsynonymous substitution (Liska et al. 2014) to the specific nutri- and pharmacogenetic response is not clear, there is prior evidence indicating crucial role of Zbtb16 in glucose homeostasis, particularly in regulating hepatic gluconeogenesis (Chen et al. 2014). We could speculate that a dysregulation of peroxisome proliferator-activated receptor $\gamma$ coactivator $1 \alpha$ (PGC-1 $\alpha$ ) /glucocorticoid receptor - Zbtb16 crosstalk may lead to increased or more sustained Zbtb16 effect triggering greater induction of hepatic gluconeogenesis and more effective impairment of insulin signaling (Chen et al. 2014). The activation hypothesis is further supported by our observation in heterozygous SHRZbtb16 knockout rats showing improved glucose tolerance and increased insulin sensitivity of peripheral tissues (Liska et al. 2017).

Table 1. Morphometric and metabolic profiles of male rats.

\begin{tabular}{|c|c|c|c|c|c|c|c|}
\hline & SHR control & $\begin{array}{c}\text { SHR-Zbtb16 } \\
\text { control }\end{array}$ & $\begin{array}{c}\text { SHR prog. + } \\
\text { HSD }\end{array}$ & $\begin{array}{l}\text { SHR-Zbtb16 } \\
\text { prog. + HSD }\end{array}$ & $\begin{array}{l}\text { p ANOVA } \\
\text { (STRAIN) }\end{array}$ & $\begin{array}{c}\text { p ANOVA } \\
\text { (DIET) }\end{array}$ & $\begin{array}{c}\text { p ANOVA } \\
\text { (STRAIN* } \\
\text { DIET) }\end{array}$ \\
\hline Weight (g) & $293 \pm 7$ & $303 \pm 4$ & $309 \pm 6$ & $298 \pm 7$ & ns & ns & ns \\
\hline Heart $\mathrm{g} / 100 \mathrm{~g} b . w t$ & $0.38 \pm 0.005$ & $0.39 \pm 0.003$ & $0.41 \pm 0.019$ & $0.40 \pm 0.001$ & $\mathrm{~ns}$ & ns & ns \\
\hline Liver $g / 100 \mathrm{~g} b . w t$. & $2.72 \pm 0.03$ & $2.77 \pm 0.03$ & $2.88 \pm 0.04^{*}$ & $2.91 \pm 0.04^{*}$ & $\mathrm{~ns}$ & 0.000124 & ns \\
\hline Kidneys $\mathrm{g} / 100 \mathrm{~g}$ b. wt. & $0.71 \pm 0.009$ & $0.66 \pm 0.006^{\mathrm{C}}$ & $0.65 \pm 0.009^{* * *}$ & $0.65 \pm 0.003$ & 0.006615 & 0.000138 & 0.009447 \\
\hline Adrenals $\mathrm{g} / 100 \mathrm{~g} \mathrm{~b} . \mathrm{wt}$. & $0.014 \pm 0.001$ & $0.014 \pm 0.001$ & $0.013 \pm 0.001$ & $0.015 \pm 0.001$ & ns & ns & ns \\
\hline RPFP g/100 g b.wt. & $0.97 \pm 0.07$ & $0.74 \pm 0.04$ & $1.17 \pm 0.04^{*}$ & $1.12 \pm 0.11^{* *}$ & 0.028680 & 0.000038 & ns \\
\hline EFP $g / 100 \mathrm{~g}$ b. wt. & $0.88 \pm 0.03$ & $0.76 \pm 0.01^{\mathrm{A}}$ & $1.02 \pm 0.03^{*}$ & $0.99 \pm 0.04^{* * *}$ & 0.012476 & $6.60 \mathrm{E}-08$ & ns \\
\hline BFP g/100 g b. wt. & $0.07 \pm 0.004$ & $0.05 \pm 0.004^{\mathrm{B}}$ & $0.10 \pm 0.004^{* * *}$ & $0.10 \pm 0.002^{* * *}$ & 0.029883 & $5.30 \mathrm{E}-12$ & $\mathrm{~ns}$ \\
\hline Fasting glucose (mmol/l) & $2.9 \pm 0.1$ & $2.6 \pm 0.1$ & $2.7 \pm 0.1$ & $2.6 \pm 0.1$ & ns & ns & ns \\
\hline Fasting insulin (nmol/l) & $48.5 \pm 3$ & $52.9 \pm 4$ & $85.4 \pm 7^{* * *}$ & $76 \pm 6^{*}$ & $\mathrm{~ns}$ & 0.000009 & ns \\
\hline $\begin{array}{l}\text { Fasting total cholesterol } \\
(\mathrm{mmol} / \mathrm{l})\end{array}$ & $32.5 \pm 2$ & $39.1 \pm 2^{* *}$ & $31.1 \pm 1$ & $33.7 \pm 2^{*}$ & 0.005575 & 0.031042 & ns \\
\hline $\begin{array}{l}\text { Fasting total triacylgly- } \\
\text { cerols (mmol/l) }\end{array}$ & $17.8 \pm 2$ & $24.6 \pm 2$ & $28.6 \pm 2^{*}$ & $29.5 \pm 3$ & $\mathrm{~ns}$ & 0.002092 & $\mathrm{~ns}$ \\
\hline
\end{tabular}

HSD: high-sucrose diet, b. wt.: body weight, prog: programmed (exposed to maternal HSD feeding), RPFP: retroperitoneal fat pad, EFP: epididymal fat pad, BFP: interscapular brown fat pad, ns: not significant. The levels of significance of pair-wise comparisons (post hoc Tukey's test) are indicated as follows: ${ }^{*} p<0.05,{ }^{*} p<0.01, * * * p<0.001$ for programming effect within a single strain; ${ }^{A} p<0.05$, ${ }^{B} p<0.01,{ }^{C} p<0.001$ for SHR vs. SHR-Zbtb16 comparison within the same dietary regimen.

Total Ch was higher in control SHR-Zbtb16 compared to control SHR. Exposure to HSD led to total Ch decrease exclusively in SHR-Zbtb16 and no change in SHR, resulting in comparable Ch concentrations in HSDexposed groups (Table 1). Upon closer examination in 20 lipoprotein subclasses, the decrease of cholesterol concentrations in SHR-Zbtb16 was most evident in majority of LDL particle classes and in very large and large HDL (Fig. 1B). The cholesterol content of medium to small LDL was decreased also in HSD-exposed SHR, however, the strain-specific (nutrigenetic) interaction was particularly apparent in very large and large HDL classes, containing most of the cholesterol (Fig. 1B). Total TAG were significantly higher in HSD-exposed SHR compared to the control group, the change of total TAG in SHR-Zbtb16 did not reach the significance threshold. 

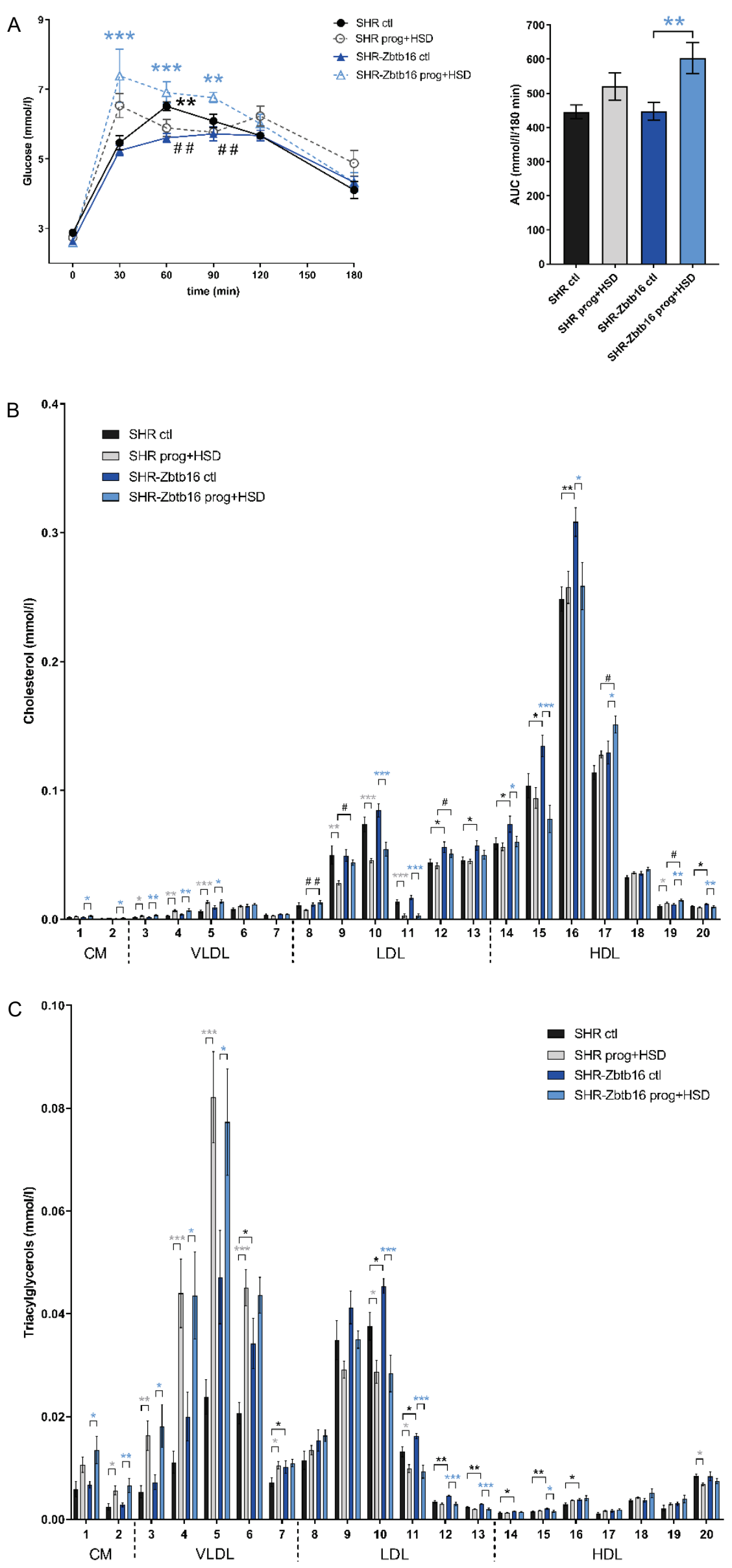

Fig. 1. (A). The oral glucose tolerance test. The course of glycemic curves in SHR male offspring (control - black circles, programmed (prog) + HSD - gray empty circles), SHR-Zbtb16 male offspring (control - dark blue triangles, prog + HSD - light blue empty triangles) during OGTT. Data are expressed as mean \pm SEM. The significance levels for strain comparison using the post hoc Fisher's least significant difference test of two-way ANOVA for STRAIN and DIET as major factors are indicated as follows: $* * p<0.01, * * * p<0.001$. Effect of HSD exposure in SHR-Zbtb16 strain shown by blue asterisks $(*)$. (A) Black asterisk $(*)$ represents STRAIN differences between SHR and SHR-Zbtb16 control males, $\mathrm{t}=60 \mathrm{~min} * *$, which was higher in SHR control males. Black hashtag ( $\left(^{\#}\right)$ represents STRAIN differences between SHR and SHR-Zbtb16 males exposed to HSD, $\mathrm{t}=60$ min **, $\mathrm{t}=90$ min $* *$, which were both higher in SHR-Zbtb16. (B, C). Lipoprotein profile. The cholesterol and triacylglycerol content in 20 lipoprotein subfractions in adult SHR control male offspring (dark grey bars), SHR-Zbtb16 control male offspring (dark blue bars), programmed SHR male offspring exposed to HSD (gray bars), programmed SHR-Zbtb16 male offspring exposed to HSD (light blue bars). Data are expressed as mean \pm SEM. The significance levels for strain comparison using the post-hoc Fisher's least significant difference test of the two-way ANOVA for STRAIN and DIET as major factors are indicated as follows: $* p<0.05$, $* * p<0.01, * * * p<0.001$. Effect of HSD exposure in SHR strain is represented by gray asterisks $\left(^{*}\right)$, in SHR-Zbtb16 strain by blue asterisks (*). (B) Black asterisk $(*)$ represents STRAIN differences between SHR and SHR-Zbtb16 control males, $\mathrm{C} 12 *, \mathrm{C} 13 *, \mathrm{C} 14 *, \mathrm{C} 15 *$, $\mathrm{C} 16 * *, \mathrm{C} 20 *$, which were all higher in SHR-Zbtb16 control males. Black hashtag $\left({ }^{\#}\right)$ represents STRAIN differences between SHR and SHR-Zbtb16 males exposed to $\mathrm{HSD}, \mathrm{C} 8 * *, \mathrm{C} 9 *, \mathrm{C} 12 *$, $\mathrm{C} 17 *, \mathrm{C} 19 *$, which were all higher in SHR-Zbtb16. (C) Black asterisk (*) represents STRAIN differences between SHR and SHR-Zbtb16 control males, $\mathrm{TG} 6 *, \mathrm{TG} 7 *, \mathrm{TG} 10 *, \mathrm{TG} 11 *, \mathrm{TG} 12 * *$, TG13 **, TG14*, TG15**, TG16*, which were all higher in SHR-Zbtb16. 
As presented in Figure $1 \mathrm{C}$, the pattern of reaction to HSD exposure was similar between the two strains for chylomicrons and VLDL, though the increase of TAG content was clearly more pronounced in SHR. We observed significant STRAIN*DIET interactions for the two classes of smallest LDL particles as their TAG content decreased in SHR-Zbtb16 and did not change in SHR in response to HSD. Rise in TAG and no change or even decrease of cholesterol in response to sucrose-rich diet has been reported earlier (Cahova et al. 2007, Jameel et al. 2014). Heterozygous targeted SHRZbtb $16^{+-}$male rats showed decreased concentrations of total serum and hepatic cholesterol and TAG (Liska et al. 2017). ZBTB16 gene variation was also associated with total and LDL cholesterol levels in a cohort of Caucasian adults (Bendlova et al. 2017). The obtained results do not provide a direct mechanistic explanation connecting the variation in Zbtb16 gene to the observed strain-specific metabolic effects of HSD. However, given the important role of Zbtb16 in adipose tissue metabolism (Plaisier et al. 2012, Wei et al. 2018), it is possible that distinct changes in substrate utilization in the two compared strains resulted in the observed shifts of lipid profiles.

The presented results reflect particular developmental stages and durations of exposition to HSD based on our previous results (Sedova et al. 2007, Skolnikova et al. 2017); different designs would be necessary to address the importance of specific "developmental windows" (Kunes and Zicha 2006). In summary, we provide evidence of nutrigenetic interaction between Zbtb16 and high-sucrose diet in context of pathogenesis of metabolic syndrome in an experimental model.

\section{Conflict of Interest}

There is no conflict of interest.

\section{Acknowledgements}

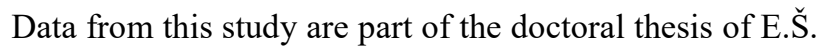
This work was supported by Charles University in Prague [GAUK 132415, PROGRES-Q25/LF1, SVV 260516] and Ministry of Health, Czech Republic - conceptual development of research organization 64165, General University Hospital in Prague, Czech Republic).

\section{References}

BENDLOVA B, VANKOVA M, HILL M, VACINOVA G, LUKASOVA P, VEJRAZKOVA D, SEDOVA L, SEDA O, VCELAK J: ZBTB16 gene variability influences obesity-related parameters and serum lipid levels in Czech adults. Physiol Res 66 (Suppl 3): S425-S431, 2017. https://doi.org/10.33549/physiolres.933731

BURESOVA M, ZIDEK V, MUSILOVA A, SIMAKOVA M, FUCIKOVA A, BILA V, KREN V, KAZDOVA L, DI NICOLANTONIO R, PRAVENEC M: Genetic relationship between placental and fetal weights and markers of the metabolic syndrome in rat recombinant inbred strains. Physiol Genomics 26: 226-231, 2006. https://doi.org/10.1152/physiolgenomics.00056.2006

CAHOVA M, VAVRINKOVA H, KAZDOVA L: Glucose-fatty acid interaction in skeletal muscle and adipose tissue in insulin resistance. Physiol Res 56: 1-15, 2007.

DEHGHAN M, MENTE A, ZHANG X, SWAMINATHAN S, LI W, MOHAN V, IQBAL R, KUMAR R, WENTZELVILJOEN E, ROSENGREN A, AMMA LI, AVEZUM A, CHIFAMBA J, DIAZ R, KHATIB R, LEAR S, LOPEZ-JARAMILLO P, LIU X, GUPTA R, MOHAMMADIFARD N, GAO N, OGUZ A, RAMLI AS, SERON P, SUN Y, SZUBA A, TSOLEKILE L, WIELGOSZ A, YUSUF R, HUSSEIN YUSUFALI A, TEO KK, RANGARAJAN S, DAGENAIS G, BANGDIWALA SI, ISLAM S, ANAND SS, YUSUF S, PROSPECTIVE URBAN RURAL EPIDEMIOLOGY STUDY I: Associations of fats and carbohydrate intake with cardiovascular disease and mortality in 18 countries from five continents (PURE): a prospective cohort study. Lancet 390: 2050-2062, 2017. https://doi.org/10.1093/ajcn/nqz348

FABIANI R, NALDINI G, CHIAVARINI M: Dietary patterns and metabolic syndrome in adult subjects: a systematic review and meta-analysis. Nutrients 11: 2056, 2019. https://doi.org/10.3390/nu11092056

FLEMING TP, WATKINS AJ, VELAZQUEZ MA, MATHERS JC, PRENTICE AM, STEPHENSON J, BARKER M, SAFFERY R, YAJNIK CS, ECKERT JJ, HANSON MA, FORRESTER T, GLUCKMAN PD, GODFREY KM: Origins of lifetime health around the time of conception: causes and consequences. Lancet 391: 1842-1852, 2018. https://doi.org/10.1016/s0140-6736(18)30312-x 
HANSON MA, GLUCKMAN PD: Early developmental conditioning of later health and disease: physiology or pathophysiology? Physiol Rev 94: 1027-76, 2014. https://doi.org/10.1152/physrev.00029.2013

HOFFMAN DJ, REYNOLDS RM, HARDY DB: Developmental origins of health and disease: current knowledge and potential mechanisms. Nutr Rev 75: 951-970, 2017. https://doi.org/10.1093/nutrit/nux053

CHEN S, QIAN J, SHI X, GAO T, LIANG T, LIU C: Control of hepatic gluconeogenesis by the promyelocytic leukemia zinc finger protein. Mol Endocrinol 28: 1987-1998, 2014. https://doi.org/10.1210/me.2014-1164

JAMEEL F, PHANG M, WOOD LG, GARG ML: Acute effects of feeding fructose, glucose and sucrose on blood lipid levels and systemic inflammation. Lipids Health Dis 13: 195, 2014. https://doi.org/10.1186/1476-511x-13-195

KHAN TA, SIEVENPIPER JL: Controversies about sugars: results from systematic reviews and meta-analyses on obesity, cardiometabolic disease and diabetes. Eur J Nutr 55: 25-43, 2016. https://doi.org/10.1007/s00394-016$\underline{1345-3}$

KRUPKOVA M, LISKA F, KAZDOVA L, SEDOVA L, KABELOVA A, KRENOVA D, KREN V, SEDA O: SingleGene congenic strain reveals the effect of Zbtb16 on dexamethasone-induced insulin resistance. Front Endocrinol (Lausanne) 9: 185, 2018. https://doi.org/10.3389/fendo.2018.00185

KUNES J, VANECKOVA I, MIKULASKOVA B, BEHULIAK M, MALETINSKA L, ZICHA J: Epigenetics and a new look on metabolic syndrome. Physiol Res 64: 611-620, 2015. https://doi.org/10.33549/physiolres.933174

KUNES J, ZICHA J: Developmental windows and environment as important factors in the expression of genetic information: a cardiovascular physiologist's view. Clin Sci (Lond) 111: 295-305, 2006. https://doi.org/10.1042/cs20050271

LISKA F, LANDA V, ZIDEK V, MLEJNEK P, SILHAVY J, SIMAKOVA M, STRNAD H, TRNOVSKA J, SKOP V, KAZDOVA L, STARKER CG, VOYTAS DF, IZSVAK Z, MANCINI M, SEDA O, KREN V, PRAVENEC M: Downregulation of Plzf gene ameliorates metabolic and cardiac traits in the spontaneously hypertensive rat. Hypertension 69: 1084-1091, 2017. https://doi.org/10.1161/hypertensionaha.116.08798

LISKA F, MANCINI M, KRUPKOVA M, CHYLIKOVA B, KRENOVA D, SEDA O, SILHAVY J, MLEJNEK P, LANDA V, ZIDEK V, D' AMATI G, PRAVENEC M, KREN V: Plzf as a candidate gene predisposing the spontaneously hypertensive rat to hypertension, left ventricular hypertrophy, and interstitial fibrosis. Am J Hypertens 27: 99-106, 2014. https://doi.org/10.1093/ajh/hpt156

NICHOLAS LM, OZANNE SE: Early life programming in mice by maternal overnutrition: mechanistic insights and interventional approaches. Philos Trans R Soc Lond B Biol Sci 374: 20180116, 2019. https://doi.org/10.1098/rstb.2018.0116

PAUSOVA Z, PAUS T, SEDOVA L, BERUBE J: Prenatal exposure to nicotine modifies kidney weight and blood pressure in genetically susceptible rats: a case of gene-environment interaction. Kidney Int 64: 829-835, 2003. https://doi.org/10.1046/j.1523-1755.2003.00172.x

PLAISIER CL, BENNETT BJ, HE A, GUAN B, LUSIS AJ, REUE K,VERGNES L: Zbtb16 has a role in brown adipocyte bioenergetics. Nutr Diabetes 2: e46, 2012. https://doi.org/10.1038/nutd.2012.21

SEDA O, KAZDOVA L, KRENOVA D, KREN V: Rosiglitazone improves insulin resistance, lipid profile and promotes adiposity in a genetic model of metabolic syndrome X. Folia Biol (Praha) 48: 237-241, 2002.

SEDA O, LISKA F, PRAVENEC M, VERNEROVA Z, KAZDOVA L, KRENOVA D, ZIDEK V, SEDOVA L, KRUPKOVA M, KREN V: Connexin 50 mutation lowers blood pressure in spontaneously hypertensive rat. Physiol Res 66: 15-28, 2017a. https://doi.org/10.33549/physiolres.933432

SEDA O, SEDOVA L, VCELAK J, VANKOVA M, LISKA F, BENDLOVA B: ZBTB16 and metabolic syndrome: a network perspective. Physiol Res 66 (Suppl 3): S357-S365, $2017 \mathrm{~b}$. https://doi.org/10.33549/physiolres.933730

SEDOVA L, KAZDOVA L, SEDA O, KRENOVA D, KREN V: Rat inbred PD/cub strain as a model of dyslipidemia and insulin resistance. Folia Biol (Praha) 46: 99-106, 2000. https://doi.org/10.2217/pgs.09.113

SEDOVA L, SEDA O, KAZDOVA L, CHYLIKOVA B, HAMET P, TREMBLAY J, KREN V, KRENOVA D: Sucrose feeding during pregnancy and lactation elicits distinct metabolic response in offspring of an inbred genetic model of metabolic syndrome. Am J Physiol Endocrinol Metab 292: E1318-E1324, 2007. https://doi.org/10.1152/ajpendo.00526.2006 
SKOLNIKOVA E, SEDOVA L, KRENOVA D, KREN V, SEDA O: Mutation in ZBTB16 gene plays a role in lipid profiles of pregnant rats and their offspring after high-sucrose diet feeding. Atherosclerosis 263: e36-e37, 2017. https://doi.org/10.1016/j.atherosclerosis.2017.06.136

USUI S, HARA Y, HOSAKI S, OKAZAKI M: A new on-line dual enzymatic method for simultaneous quantification of cholesterol and triglycerides in lipoproteins by HPLC. J Lipid Res 43: 805-814, 2002.

WEI S, ZHANG M, ZHENG Y, YAN P: ZBTB16 overexpression enhances white adipogenesis and induces brown-like adipocyte formation of bovine white intramuscular preadipocytes. Cell Physiol Biochem 48: 2528-2538, 2018. https://doi.org/10.1159/000492697 